\title{
Primary care research and musculoskeletal medicine
}

\author{
Peter Croft, George M. Peat and Danielle A. Van Der Windt
}

Arthritis Research Campaign National Primary Care Centre, Keele University, Madeley Road, Keele ST5 5BG, UK

\begin{abstract}
Musculoskeletal symptoms are frequent in primary care, and back pain and osteoarthritis are the commonest causes of disability in the developed world. Effective primary care could make a real difference to population levels of pain and disability. Traditional approaches, which see musculoskeletal pain only as a guide to underlying pathology, underestimate the need to assess and manage pain and disability in their own right. This paper presents the rationale for new models of diagnosis and care. These include: placing symptoms and their impact on daily life at the centre of primary care management of common musculoskeletal syndromes; a focus on the person with co-morbidity rather than on neatly parcelled distinctive single musculoskeletal diagnoses; promotion of positive messages such as the safety of activity and the efficacy of simple treatments; inclusion of the psychological and social context in management of musculoskeletal conditions; supporting patients to live and participate in daily life despite their pain or disability; supporting and training health care professionals other than doctors to provide a 'gatekeeping' role for these conditions; evaluation of changes in the organisation of care for patients with musculoskeletal problems. Evidence for the effectiveness of such new models is uneven. The paper reviews other research directions, such as qualitative research into patient perceptions and priorities, and the idea that non-specific treatment effects (eg, acupuncture) are often bigger than specific effects and could be harnessed to improve clinical care. Natural history studies remain important for understanding causation: prevalence is already near lifetime maximum by young adulthood for example and we do not know why. Musculoskeletal medicine is the Cinderella of primary care and primary care research. Knowledge, training and enthusiasm lags behind other priority areas for primary care clinicians. Yet the potential benefits, which primary care could achieve, are enormous.
\end{abstract}

Key words: back pain; chronic disease management; disability; musculoskeletal pain; osteoarthritis; primary care

Received 14 August 2009; accepted 19 October 2009; first published online 3 December 2009

\section{Introduction}

Musculoskeletal medicine is important to primary care for a number of reasons. Musculoskeletal symptoms are common and most are dealt with informally by a combination of care obtained

Correspondence to: Peter Croft, Arthritis Research Campaign National Primary Care Centre, Keele University, Madeley Road, Keele ST5 5BG, UK. Email: p.r.croft@cphc.keele.ac.uk outside the health system, such as self-care, overthe-counter prescriptions and complementary therapies (eg, Blyth et al., 2005). Collectively, they also represent the second most frequent reason for consulting in general practice in the UK (McCormick et al., 1995).

Musculoskeletal problems such as back pain and osteoarthritis are the main cause of disability in the developed world, and are likely to increasingly dominate the picture of disability at a 
population level as the demographic structure of society changes and the mortality of the major diseases continues to decline (Jagger et al., 2006). Together with mental illness, musculoskeletal problems represent the most frequent reason for short- and long-term absence from the workplace on health grounds in many developed countries (Waddell, 2004). This makes musculoskeletal problems a public health issue.

Many public health targets, currently regarded as important (obesity, injury, physical inactivity and mental ill-health) can cause or prolong musculoskeletal problems (eg, Felson et al., 2000; Jinks et al., 2006; Patten et al., 2008). If these targets are being tackled, in their own right or as a means to reduce heart disease mortality, for example, an additional and important consequence will be a reduction in the occurrence of pain and disability linked to musculoskeletal problems.

However, because musculoskeletal problems are so frequently brought to the attention of primary care, effective care of people with these complaints in that setting could also make a real difference to population levels of pain and disability by promoting secondary prevention, supporting self-management, and offering best care.

In this paper, we review some of the current ideas and concepts driving the clinical, research and policy agendas in primary care related to this clinical topic. Although there are some 160 different musculoskeletal problems specified in morbidity coding systems, the focus in this paper will be on the most common ones, notably low back pain and joint pain in older people (clinical osteoarthritis).

\section{Shifting the conceptual model 1: from diseases to symptoms}

Death is rarely caused by musculoskeletal problems and in most countries this fact keeps them low on both the scientific and clinical agendas (Woolf and Akesson, 2001). The traditional model of medicine and medical science, which attempts to attribute musculoskeletal symptoms to a histopathological diagnosis and to a mechanism close to the location of the joint pain or the muscle stiffness, has had some notable successes such as joint replacement for osteoarthritis. General disease models have also had some success, notably in the development of therapeutic innovations for inflammatory arthritis, an important but rare component of primary care musculoskeletal workload.

However, the regional pathology model has hindered the development of a rational and effective approach to prevention and management of common musculoskeletal syndromes. An approach that considers pain only to be a guide to underlying pathology ignores the status of pain and its related disability as problems that need assessment and management in their own right.

Medical diagnosis of musculoskeletal problems is rarely a strong indicator of the levels of disability. Prognostic features that explain variation in musculoskeletal outcomes in primary care, such as pain severity and psychological distress, are common to different syndromes (Mallen et al., 2007). Von Korff's approach to classification of chronic pain based on such features uproots the emphasis in primary care from the diagnosis to the pain itself and its likely future course (Von Korff and Miglioretti, 2005), a generic approach relevant and applicable to many common musculoskeletal pains (Peat et al., 2006; Thomas et al., 2008). These findings reinforce the idea that regional syndromes of musculoskeletal pain, assumed in textbooks to be distinctive pathological diseases, are variations of a common problem of chronic pain.

The main diagnosis provided for back pain by general practitioners (GPs) in the UK in 1970 was spinal osteoarthritis (Royal College of GPs, 1979); by 1991 'back pain unspecified' was the most frequent code (McCormick et al., 1995). Waddell has traced the catastrophic story of the regional pathological approach to pain as applied to the back, which among other things resulted in much unnecessary back pain surgery (Waddell, 2004). GPs vary also in their use of the 'osteoarthritis' label, often meaning 'the older person presenting with joint pain' (Bedson et al., 2004).

This is not to argue against the tenets of clinical diagnosis. Understanding and knowledge of pathology clearly have important roles in guiding management of many musculoskeletal conditions fracture, gout, inflammatory arthritis - but the need in primary care literature, as highlighted elsewhere (Foster et al., 2003), is to understand

Primary Health Care Research \& Development 2010; 11: 4-16 
that the management of musculoskeletal problems is broader than this. Yet scientific sounding musculoskeletal terms are still used to give spurious diagnostic labels to a patient's symptoms with little empirical justification. This overemphasis on diagnosis and attempts at cure does little to address the prevention of chronic pain and disability.

The conceptual shift is to place symptoms and their impact on daily life at the centre of primary care management of common musculoskeletal syndromes. New models are needed to explain their occurrence and why symptoms persist in some people and not others. Neurophysiologists have supplied biological reasons for dealing with pain in its own right rather than as a phenomenon exclusively related to underlying tissue pathology (Siddall and Cousins, 2004). Current work on the neurophysiology of pain and its persistence, and on an individual's life-long propensity to develop chronic symptoms, is uncovering mechanisms that integrate biological, psychological and social components of musculoskeletal pain, and which do not depend on the continuing presence of regional injury or inflammation as the sole or major explanation of symptom persistence (eg, Nielsen and Henriksson, 2007).

\section{Shifting the conceptual model 2: from single syndromes to chronicity and multi-morbidity}

Causes identified as common to many musculoskeletal syndromes reflect targets for prevention and early management. Weight control and increased muscle strengthening activity would reduce population levels of back and regional pain and of radiographic and symptomatic osteoarthritis in the lower limb (25-26).

Although genetic studies may help to identify persons more prone to severe inflammatory diseases such as rheumatoid and lupus ( $\mathrm{Li}$ and Begovich, 2009), these conditions are rare causes of musculoskeletal pain and disability, and it is unclear whether the identification of genetic components of common syndromes such as back pain will prove useful. Specific causes of musculoskeletal syndromes such as work injury are important in individual cases, and provide targets for prevention (Punnett et al., 2005), but

Primary Health Care Research \& Development 2010; 11: 4-16 again only explain a small proportion of all musculoskeletal pain seen and treated in primary care.

Given that acute pain and injury are so common, a part of the life of the human musculoskeletal system, and that acute symptoms often resolve quickly, the major research concern is the persistence and recurrence of symptoms and disability that disrupt life in the long-term. There is clear evidence that the conceptual model for such persistence must include psychological and social factors (Gatchel et al., 2007). This bio-psychosocial model, as most GPs are well aware, applies not only to musculoskeletal conditions but also to many other common symptoms in primary care.

The concurrence of different chronic symptoms and diseases in the same person, and of factors common to the onset and persistence of each one, are crucially important areas of research in musculoskeletal medicine. The most frequent co-morbidity is the co-existence of two or more musculoskeletal conditions (Britt et al., 2008). Kadam has shown the high frequency of co-morbid disease and illness in patients consulting for osteoarthritis in primary care (Kadam et al., 2009). Substantial co-morbidity is found between chronic pain and 'functional syndromes' such as fatigue and irritable bowel (Aggarwal et al., 2006; Kanaan et al., 2007). Some is explained by chance concurrence when conditions occur frequently in the general population, and some by the common factor of age, but not all can be explained in this way. Other causes include common pathologies (inflammation in the case of osteoarthritis and coronary heart disease for example), psychological influences on chronicity, social factors or the effect of treating one condition on another. From a clinical perspective, primary care is often and increasingly about the person with co-morbidity rather than neatly parcelled distinctive single musculoskeletal problems (Carnes et al., 2007).

The evidence is emerging that, if chronicity reflects an individual's propensity to develop persistent problems rather than a simple consequence of onset of a symptom, the life-course approach is crucial to understanding aetiology and course of chronic conditions. If some people were prone to developing chronic illness when exposed to a trigger (eg, injury), this would explain the trajectories in pain that have been observed from childhood to adulthood (Mallen et al., 2006a; 
2006b). The link between number of reported pains and extent of disability and poor health is consistent across different societies and cultures (Gureje et al., 2008; Kamaleri et al., 2008) and in childhood and adolescence (Larsson and Sund, 2007). Furthermore long-term follow-up of young and older Norwegian adults suggests number of reported pains is stable from young ages (Kamaleri et al., 2009), and multiple pains are more common in children whose mothers have multiple pains (Saunders et al., 2007). Genetics may have a more obvious role to play in the investigation of this broad propensity than in delineating preventable causes of individual syndromes.

\section{Shifting the lay model: from 'nothing to be done because it's just part of life' to more positive views}

Musculoskeletal problems are a fact of life rather than a disease. European adults on average report three recent significant sites of pain, mostly musculoskeletal, at any one time (Kamaleri et al., 2009). Musculoskeletal discomfort is inevitable in a moving organ system such as the human locomotor apparatus, which is prone to dysfunction as part of the ebb and flow of daily life.

However, this inevitability of aches, strains and pains may result in attitudes and beliefs that counteract the potential for reducing their impact on everyday life. Older people often view symptoms as part of 'growing old' and not a reason for troubling the doctor, despite their impact on daily life (Stoller et al., 1993). Among doctors and patients, such perceptions may be linked to a sense that 'there is nothing to be done' about the problem (Ong and Hooper, 2006). This diminishes the opportunity for active and positive approaches to care. For example, what is more remarkable - that $40 \%$ of 80 year olds have definite radiographic evidence of osteoarthritis in their knee (with or without symptoms), or that $60 \%$ of 80 year olds, after a lifetime of mechanical insults to the joint, do not have it, even though some may have symptoms (Felson et al., 1987)?

At the same time, musculoskeletal problems such as back pain are the major reason for informal lay networks of care and advice and for expendi- ture on health outside the health care system in Europe and America. In the UK Artus found that most patients with knee osteoarthritis attending their GP were also using complementary therapies for their pain (Artus et al., 2007).

This poses a dilemma. A biomedical approach has been unproductive for many common musculoskeletal problems in primary care. An approach that says 'it is just life, put up with it' seems equally negative. So how to promote the idea that there is something to be done, while avoiding over-medicalisation of common problems? Research evidence from the last 20 years suggests that, among other things, this can be achieved by positive messages about the safety of activity ('avoid bed rest' for back pain for example (Deyo et al., 1986)), the benefits of work, the efficacy of simple treatments for back pain and clinical osteoarthritis, and possibly supported self-care.

Although guidelines vary, Keller et al. (2007) found small but beneficial effects for a range of simple back pain treatments, both active and passive. The authors regarded this as highlighting a need for radical new treatments. An alternative view is that, put into practice widely and effectively and efficiently, these interventions could deliver substantial population effects.

There are also evidence-based advantages of avoiding investigation and referral when these are not needed. Avoiding things that harm or do not help is as important a component of guidelines for osteoarthritis and back pain as recommendations for what might help (Chou et al., 2009; Savigny et al., 2009).

Crucial to all this is the potential for changing public and professional attitudes, from 'there's nothing to be done' because it is about degenerating joints, to 'there is plenty to be tried'. Cultural beliefs and attitudes could provide important targets if population levels of pain, disability and work loss are to be reduced. The impact of mass media campaigns designed to change attitudes and behaviour related to back pain (eg, 'stay active') has been investigated in randomised controlled trials. Three studies (Buchbinder and Jolley, 2007; Waddell et al., 2007; Werner et al., 2008) have concluded that public and professional beliefs and attitudes change as a result but only in Australia (Buchbinder and Jolley, 2007) did this translate to changes in

Primary Health Care Research \& Development 2010; 11: 4-16 
behaviour and disability such as reduced sickness absence from work.

\section{Shifting the model of care: from diagnosis and investigation to a bio-psychosocial model of care}

Changes in traditional medical attitudes to musculoskeletal syndromes and their care are gradually translating to changes in clinical approaches. This draws on a broader understanding of biological and psychosocial influences on the development and persistence of musculoskeletal symptoms, and does not reject a search for important pathology but shifts the emphasis to other components of the problem.

The shift in perspective has driven wider policy change. A triage approach to back pain for example has been widely promoted in primary care, and the psychological and social drivers of work loss attributed to back pain increasingly acknowledged (Staal et al., 2003). The 'triage revolution' has reduced many surgical waiting lists for back pain in the UK. GPs and physiotherapists have been willing to advise against bed rest and promote exercise (Bishop et al., 2008a; 2008b), although a significant minority have not made this shift (Fritz et al., 2007; Bishop et al., 2008a; 2008b). Complex mechanical treatments in the physiotherapists' armoury, such as ultrasound and traction, have been questioned (eg, Dziedzic et al., 2005; Ainsworth et al., 2007).

The World Health Organisation's International Classification of Function provides a framework in which tissue damage may be a relatively small component of a musculoskeletal problem, and psychological, social and cultural contexts contribute to outcome (Stucki et al., 2007), and participation in social and domestic life is an important outcome in its own right (WHO, 2001; Wilkie et al., 2007). Desired outcomes are increasingly orientated to the patient's perspective, less about fixing disease than helping people do what they want despite their musculoskeletal problem. There is a new focus on assessing an individual's risk of developing chronic pain and helping them to reduce it (eg, by reducing work stress) rather than depending on passive treatments (eg, spinal manipulation) alone.

Primary Health Care Research \& Development 2010; 11: 4-16
The search for empirical evidence of what works best needs to continue. This is how the 'avoid bed rest' argument came about in back pain (Deyo et al., 1986) and 'avoid over-investigation' was highlighted. Routine magnetic resonance imaging (MRI) scans for back pain for example result in more diagnoses and more treatments, with no impact on overall outcome (Jarvik et al., 2003). Caution is needed about extrapolating trial results to everyone - pain severity may make rest the only option, some will benefit from MRI scans. But 'on average', patients can often be treated simply and straightforwardly in primary care with no loss of effect. Simple advice and exercise for neck pain is as good as many more complex therapies for example (Dziedzic et al., 2005), and the same is true for back and knee pain (Porcheret et al., 2007; Zhang et al., 2008; Savigny et al., 2009). The triage clinic can safely identify the many low risk patients and deal with them straightforwardly, even though the validity and usefulness of 'red flags' in back pain as indicators of serious disease has been questioned (Henschke et al., 2007).

Musculoskeletal primary care science is in its infancy. We consider its driving concepts to be that pain and disability should be the focus of models of care for common syndromes and that attempts to 'cure' may be one factor in chronicity. Attention has moved towards supporting patients to learn how to live and participate in daily life despite the impairment or the pain. This is not just about education and behavioural principles directed at beliefs and attitudes and promoting a positive approach, but about practical interventions to support self-management such as problem-solving and graded exercise (eg, Hay et al., 2006; Bigos et al., 2009) or more specialised approaches such as the Alexander technique (Little et al., 2008). There is variable evidence of the effect of such approaches, although they have been tested to an extent (eg, Buszewicz et al., 2006; Hay et al., 2006; Little et al., 2008), and more empirical work is needed. The danger is that this could all degenerate into lifestyle formulae in which the main output is that everyone feels temporarily uplifted, inspired or motivated, but which dissipates in the cool light of critical evidence. Nevertheless, much research is being directed at tackling specific components of such approaches in a constructive and scientific way. 


\section{Shifting the organisation of care: from GP to 'the musculoskeletal practitioner' and supported self-management}

As care shifts from secondary to primary care, and from passive treatments to self-management in the community, there are accompanying shifts from uni- to multi-disciplinary care and to supporting and training health care professionals other than doctors to undertake the 'gate-keeping' role, such as direct physiotherapy access and pharmacist advice. Evidence for these changes is uneven but growing (eg, Hay et al., 2006; Dobscha et al., 2009).

One focus of research is a broader skill mix in primary care. From the 1980s, multidisciplinary teams in specialist centres have demonstrated benefits for chronic pain patients through addressing behaviour and beliefs. The effective component of these packages is unclear, and whether behavioural change in pain patients (eg, movement rather than restriction) is best achieved by a skilled cognitive behavioural psychologist or through physical training from a skilled physiotherapist for example is not known and is debated.

There may be neither resource nor time for intensive behavioural approaches to common painful problems in primary care, which raises the question of whether behavioural principles can be effective if delivered more briefly or in a less 'skilled' way. Two trials - one with physiotherapists (Hay et al., 2005), one with GPs (Jellema et al., 2005) - have tested this but the answer remains unclear. Neither study found differences compared with usual care, but physiotherapists did deliver active 'talking' pain management with no negative consequences.

There are a number of ways forward. Bigger 'doses' of intervention might be needed. Another option, being explored by our group, is to tailor treatments more precisely to the individual. Epidemiology provides the basis for classifying back pain consulters in primary care by the likelihood they will improve (Von Korff and Dunn, 2008). The features used to do this can either be targeted for treatment in themselves (eg, depression) or used to identify a group for treatment (eg, spinal mobilisation if psychological distress is absent). Screening tools for classifying patients in this way (eg, the Orebro instrument (Westman et al., 2008), STarT Back Screening Tool (Hill et al., 2008)) have been developed or are being tested.
An alternative to psychological approaches in primary care is to provide confident physical approaches, consistent with the expectations of the patients who are coming to see a physiotherapist. There is evidence that passive treatments (manipulation and acupuncture) have some effect in back pain (eg, UKBEAM Trial Team, 2004), but the most effective physical therapies may be those that encourage self-help. Osteoarthritis self-care delivered via expert patients from a charity (Arthritis Care) improved self-efficacy in the experimental group (Buszewicz et al., 2006)), but these effects did not translate to improvements in pain and disability. Long-term follow-up is needed to establish if changes in such features as self-efficacy do eventually improve function and social participation.

The 'subgroup-and-target' approach is appealing in terms of gaining maximal effects from treatment, although advantages for the individual have yet to be demonstrated. As with any screening programme, evidence is needed that the screened population of back or musculoskeletal pain sufferers benefits. Evidence is emerging that such approaches are effective in back pain (Brennan et al., 2006).

An alternative approach is to tackle different outcomes. Shaw and colleagues have investigated primary care support for return-to-work as a desirable outcome for back pain patients. They introduced return-to-work co-ordinators linked directly with the workplace, and return-to-work rates improved. Skills in negotiation and conflict resolution were more relevant for the co-ordinators than any prior clinical training (Shaw et al., 2006).

Given the evidence that doing some things and not others is beneficial for patients with musculoskeletal pain, how to get those results into practice? Such implementation research is of particular challenge to musculoskeletal medicine when the arguments for benefit rely so much on the large numbers who have the problem and the benefits that can accrue from improving their average lot by a modest amount (as distinct from curing a very small number who have a precisely definable severe and diagnosable condition for example). Randomised controlled trials of putting results into practice have taken place with mixed results - processes improve but clinical outcomes do not (Becker et al., 2008), and qualitative

Primary Health Care Research \& Development 2010; 11: 4-16 
studies are helping to understand the reasons for this, such as GPs' awareness that standardised guidelines of care do not easily match the individual variation in patient need presented in daily practice (eg, Corbett et al., 2009).

If we accept that so-called biomedical models of disease have not served primary care musculoskeletal practice so well, and that doctors do not necessarily possess the right sort of skills or that it is an inefficient use of their time to deliver the necessary interventions, the question arises as to whether primary care should be radically changing the organisation of care for patients with musculoskeletal problems.

The expert patient innovation spawned hope for self-care delivered through information and support packages by patient groups (Lorig, 2002). The evidence is mixed for a clinical effect, although some would argue that such approaches are worth doing anyway. One problem is that people who choose to go to primary care for help are looking for some sort of professional clinical help anyway (Kennedy et al., 2004). But if, as an example, triage in hospital-based back pain services delivered by clinicians such as physiotherapists or osteopaths, has been so successful in reducing surgical waiting lists, why is this model not moved wholesale into primary care?

It may be that this is too big a leap, but research into service development and change of care models holds promise that an evidence base can be built (Eccles et al., 2009; Salisbury et al., 2009). In our Centre, we are currently studying whether change can be introduced into the language of the GP's initial consultation with joint pain consulters and whether nurses can provide more in-depth support for self-management of joint pain or occupational rehabilitation for back pain patients. Other studies have investigated methods of training GPs in assessing pain as a multidimensional problem (Huas et al., 2006) or whether other health professionals have more success in rehabilitation than doctors who concentrate exclusively on clinical aspects (eg, Shaw et al., 2006).

\section{Alternative models: non-specific effects of care}

Musculoskeletal conditions have in common with psychological illness the idea that the 'placebo'

Primary Health Care Research \& Development 2010; 11: 4-16 effect is not only strong but also desirable. The improvement usually seen in all participants in pain trials, regardless of any between-group differences, may be a tribute to natural history or the benefits of consulting someone. Such benefits may lie with the clinician, the situation, the sense of doing something, the setting, the context, and the length and content of the consultation. There is a growing body of research on the idea that these non-specific effects are bigger than specific effects of therapy and could be harnessed as an important part of clinical care (Miller and Kaptchuk, 2008).

The experience of pain as distinct from the existence of a disease to be cured is central to this argument, because non-specific effects can impact directly on symptom outcome. Anxiety and depression are other plausible examples of symptoms that might improve as a direct result of non-specific components of the consultation. The argument does not rule out the need to select the most effective therapy to offer, even if the context and style in which it is delivered provides most of the observed effect. Yet improving beneficial nonspecific effects - communication skills, consultation time and optimal method of information delivery, for example, might enhance the specific effects of therapy.

One of the things that this line of research does is to throw the emphasis back on the clinician or healthcare professional seeing the patient. The musculoskeletal field is perhaps more populated than other disease groups with clinicians who have a belief that the way that they approach the problem is the right and only true way - from orthopaedic surgeons to spinal manipulators to complementary therapists. This belief and the way that it lines up with patients' beliefs and expectations have to be accepted as potentially the most powerful component of the treatment. The paradox is that if a real specific effect of a treatment is disproved (eg, an active treatment appears no better than its placebo), then the basis for the non-specific effects of the treatment may be undermined by loss of belief or lowered expectations of effectiveness in both patient and clinician or even by the removal of the treatment from 'evidence-based' primary care. Acupuncture research highlights this paradox. Acupuncture seems better for back or knee pain than 'usual care' but active acupuncture is no better than a 
'sham' procedure identical to the real thing except for the piercing of the skin (Foster et al., 2007; Cherkin et al., 2009). This evidence justified inclusion of acupuncture in the National Institute for Health and Clinical Excellence guidelines for back pain, despite the treatment effect of acupuncture not apparently being achieved by its defining feature - the passage of a needle through the skin. A challenge of implementing research about pain relief is how to introduce the idea of evidence-based uncertainty about a treatment without undermining the beneficial effect of the patient-clinician interaction.

Important also are the beliefs and perceptions of clinicians who see and treat musculoskeletal patients and the way these might influence treatment and its outcome. Unhelpful perceptions persist among a significant proportion of doctors and physiotherapists who treat people with back pain and knee pain (Bishop et al., 2008a; 2008b; Holden et al., 2008). Whether their beliefs line up with a physical or psychosocial model of back pain influences their actions as regard management, even for something as basic as bed rest, with clinicians whose beliefs accord with a biomedical model more likely to advise rest and time off work for acute low back pain (Bishop et al., 2008a; 2008b).

\section{Natural history}

We have placed this topic here because the course of musculoskeletal conditions in primary care inevitably involves treatment - either selfmanagement by patients or routine care from a wide range of practitioners.

There is a natural history of these conditions in the community, which provides the background to the primary care story. By young adulthood, the cumulative prevalence of back pain, chronic pain and median number of different pains, in postal surveys is already near lifetime maximum estimates (Mallen et al., 2005; Kamaleri et al., 2009). Although significant numbers improve in any period, recurrence is common. About $10 \%-15 \%$ of adults at any time will be affected by disabling chronic pain (Blyth et al., 2001), and for twothirds of these it is a long-term problem (Elliott et al., 2002). Patterns shift in older people to joint pain as the dominant problem, and the proportion with pain that interferes with life increases through the older ages (Thomas et al., 2004).

There is a natural history of conditions brought to the clinician, which may or may not be related to the care provided. As Deyo described (Deyo, 1993), and Dunn (Dunn and Croft, 2006) has illustrated empirically, the patient consulting about a musculoskeletal problem will be seeking care at a point when pain levels are high, and 'regression to the mean' translates to an inevitable fall in pain levels after consultation.

Natural history studies have shown that the traditional primary care maxim (most people with musculoskeletal conditions will be better in three months) is wrong. Many do improve in the shortterm, but recurrence is the norm, as is persistence of some pain and disability long-term (Croft et al., 1998). Novel approaches have been used to summarise this. Dunn and Jordan for example have applied latent class analysis to monthly pain and disability scores in primary care patients with low back pain (Dunn et al., 2006) and identified trajectories that predict outcome and are linked with psychosocial measures.

Natural history analyses have supported the idea of identifying subgroups for targeted treatment or preventive activity. This links closely to prognosis, the clinical discipline neglected as attention historically swung to diagnosis and treatment (Hemingway, 2006). The question is whether we can predict who will improve (or at least not get worse) and how this improvement can be encouraged, and who is likely to get worse and what can be done about this. This returns us to the bio-psychosocial models about lowering risk and removing barriers to improvement. The occupational context is an important example - to identify those at risk of work incapacity and lower that risk.

\section{The experience of musculoskeletal pain}

We end with the beginning - with the patient perspective and the critical role of qualitative research in providing accounts of the experiences and perceptions of people with musculoskeletal problems, and complementary accounts drawn from people who treat them. This research has developed in ways that have dramatically expanded the involvement of users of research in shaping and managing the research agenda.

Primary Health Care Research \& Development 2010; 11: 4-16 
Interview studies have allowed an in-depth understanding of the meaning of living with pain and disability and of the interactions between clinicians and patients (eg, Chew-Graham and May, 2000; Corbett et al., 2007; Richardson et al., 2007). Such studies capture the frustration that many patients and practitioners feel when faced with the uncertainty and lack of clear management options linked with chronic pain, but also identify the ways in which adaptation and independence can improve daily life despite continuing symptoms. Qualitative research in musculoskeletal patients has a particular role to play in providing context and explanation for individual variation in epidemiological and intervention studies. Corbett (Corbett et al., 2009) for example has highlighted the conflict that GPs feel between best evidence practice and the complex problems presented by patients who do not fit the picture addressed by published research.

Engagement of patients and public in the development and direction of primary care musculoskeletal research has been strongly advocated by government agencies and in the UK by the major charities (the Arthritis Research Campaign and Arthritis Care). Jinks and colleagues (Jinks et al., 2009) established a community knee pain forum, which engaged a wide range of public, patient, policy, health and social care participants in discussing the dissemination and prioritisation of results of knee pain research. Practical research has also directly followed from engagement of clinical users in systematically setting the questions for research - for example pharmacy and physiotherapy-led management of joint pain in older people (Hay et al., 2006), and different approaches to neck pain management by physiotherapists (Dziedzic et al., 2005).

\section{Conclusions}

Musculoskeletal medicine is the Cinderella of primary care. Although it is one of primary care's largest workloads, knowledge, training and enthusiasm has lagged behind other priority areas for primary care clinicians. Yet the potential benefits, which sensible practical primary care could achieve in this field, are enormous.

Musculoskeletal medicine has also been the Cinderella of primary care research, with limited opportunities for bright new technologies and

Primary Health Care Research \& Development 2010; 11: 4-16 spectacular advance. Yet the researcher who is interested in shifting the whole way in which we view chronic pain, in exploring the powerful effects of the clinical encounter on these conditions, in changing the outcomes and targets of clinical care, in re-organising the delivery of care to provide much more power and influence for the allied health professions and nurses and in particular for the patients to manage these conditions in the frontline, this is a great area for science, from the biological to the social.

\section{Acknowledgements}

We have written this paper on behalf of all the researchers in the Arthritis Research Campaign National Primary Care Centre. The concepts and issues in the paper represent selected areas of importance in the field. In formulating these ideas over the years, we owe a great debt to the many scientists and research groups around the world who have interacted with Centre researchers and whose work has influenced us. Much of their work is not referenced or discussed specifically in the paper; our reference list is idiosyncratic, selected to provide examples rather than a comprehensive review, and much of it designed to represent the work of our Centre. The Centre's research would not have been possible without the hard work and support of all the support staff in the Centre, and our clinical and patient colleagues. Our funding comes from a range of non-commercial sources, including the Arthritis Research Campaign UK, the National Institute of Health Research UK, the Medical Research Council UK, the Wellcome Trust, and the Health Foundation. The authors also extend thanks to colleagues who read and commented on the manuscript.

\section{References}

Aggarwal, V.R., McBeth, J., Zakrzewska, J.M., Lunt, M. and Macfarlane, G.J. 2006: The epidemiology of chronic syndromes that are frequently unexplained: do they have common associated factors? International Journal of Epidemiology 35, 468-76.

Ainsworth, R., Dziedzic, K., Hiller, L., Daniels, J., Bruton, A. and Broadfield, J. 2007: A prospective double blind placebo-controlled randomized trial of ultrasound in the physical therapy treatment of shoulder pain. Rheumatology $46,815-20$. 
Artus, M., Croft, P. and Lewis, M. 2007: The use of CAM and conventional treatments among primary care consulters with chronic musculoskeletal pain. BMC Family Practice 8, 26.

Becker, A., Leonhardt, C., Kochen, M.M., Keller, S., Wegscheider, K., Baum, E., Donner-Banzhoff, N., Pfingsten, M., Hildebrandt, J., Basler, H.D. and Chenot, J.F. 2008: Effects of two guideline implementation strategies on patient outcomes in primary care: a cluster randomized controlled trial. Spine 33, 473-80.

Bedson, J., McCarney, R. and Croft, P. 2004: Labelling chronic illness in primary care: a good or a bad thing? British Journal of General Practice 54, 932-38.

Bigos, S.J., Holland, J., Holland, C., Webster, J.S., Battie, M. and Malmgren, J.A. 2009: High-quality controlled trials on preventing episodes of back problems: systematic literature review in working-age adults. Spine 9, 147-68.

Bishop, A., Foster, N.E., Thomas, E. and Hay, E.M. 2008a: How does the self-reported clinical management of patients with low back pain relate to the attitudes and beliefs of health care practitioners? A survey of UK general practitioners and physiotherapists. Pain 135, 187-95.

Bishop, A., Foster, N., Thomas, E., Main, C. and Hay, E. 2008b: The attitudes of health care practitioners influence the way they manage low back pain: results from UK general practitioners and physiotherapists. Pain 135, 187-95.

Blyth, F.M., March, L.M., Brnabic, A.J., Jorm, L.R., Williamson, M. and Cousins, M.J. 2001: Chronic pain in Australia: a prevalence study. Pain 89, 127-34.

Blyth, F.M., March, L.M., Nicholas, M.K. and Cousins, M.J. 2005: Self-management of chronic pain: a population-based study. Pain 113, 285-92.

Brennan, G.P., Fritz, J.M., Hunter, S.J., Thackeray, A., Delitto, A. and Erhard, R.E. 2006: Identifying subgroups of patients with acute/sub acute 'nonspecific' low back pain: results of a randomized clinical trial. Spine 31, 623-31.

Britt, H.C., Harrison, C.M., Miller, G.C. and Knox, S.A. 2008: Prevalence and patterns of multimorbidity in Australia. Medical Journal of Australia 189, 72-77.

Buchbinder, R. and Jolley, D. 2007: Improvements in general practitioner beliefs and stated management of back pain persist 4.5 years after the cessation of a public health media campaign. Spine 32, 156-62.

Buszewicz, M., Rait, G., Griffin, M., Nazareth, I., Patel, A., Atkinson, A., Barlow, J. and Haines, A. 2006: Selfmanagement of arthritis in primary care: randomised controlled trial. British Medical Journal 333, 879.

Carnes, D., Parsons, S., Ashby, D., Breen, A., Foster, N.E., Pincus, T., Vogel, S. and Underwood, M. 2007: Chronic musculoskeletal pain rarely presents in a single body site: results from a UK population study. Rheumatology 46, 1168-70.

Cherkin, D.C., Sherman, K.J., Avins, A.L., Erro, J.H., Ichikawa, L., Barlow, W.E., Delaney, K., Hawkes, R., Hamilton, L., Pressman, A., Khalsa, P.S. and Deyo, R.A.
2009: A randomized trial comparing acupuncture, simulated acupuncture, and usual care for chronic low back pain. Archives of Internal Medicine 169, 858-66.

Chew-Graham, C.A. and May, C. 2000: 'Partners in pain' the game of painmanship revisited. Family Practice 17, 285-87.

Chou, R., Loeser, J.D., Owens, D.K., Rosenquist, R.W., Atlas, S.J., Baisden, J., Carragee, E.J., Grabois, M., Murphy, D.R., Resnick, D.K., Stanos, S.P., Shaffer, W.O. and Wall, E.M. 2009: American Pain Society Low Back Pain Guideline Panel. Interventional therapies, surgery and interdisciplinary rehabilitation for low back pain: an evidence-based clinical practice guideline from the American Pain Society. Spine 34, 1066-77.

Corbett, M., Foster, N.E. and Ong, B.N. 2007: Living with low back pain - stories of hope and despair. Social Science and Medicine 65, 1584-94.

Corbett, M., Foster, N. and Ong, B.N. 2009: GP attitudes and self-reported behaviour in primary care consultations for low back pain. Family Practice 26, 359-64.

Croft, P., Macfarlane, G.J., Papageorgiou, A.C., Thomas, E. and Silman, A.J. 1998: The outcome of low back pain in general practice. British Medical Journal 316, 1356-59.

Deyo, R.A. 1993: Practice variations, treatment fads, rising disability. Spine 18, 2153-62.

Deyo, R.A., Diehl, A.K. and Rosenthal, M. 1986: How many days of bed rest for acute low back pain? A randomized clinical trial. New England Journal of Medicine 315, 1064-70.

Dobscha, S.K., Corson, K., Perrin, N.A., Hanson, G.C., Leibowitz, R.Q., Doak, M.N., Dickinson, K.C., Sullivan, M.D. and Gerrity, M.S. 2009: Collaborative care for chronic pain in primary care: a cluster randomized trial. Journal of the American Medicine Association 301, $1242-52$.

Dunn, K.M. and Croft, P.R. 2006: Repeat assessment improves the prediction of prognosis in patients with low back pain in primary care. Pain 126, 10-15.

Dunn, K.M., Jordan, K. and Croft, P.R. 2006: Characterizing the course of low back pain: a latent class analysis. American Journal of Epidemiology 163, 754-61.

Dziedzic, K., Hill, J., Lewis, M., Sim, J., Daniels, J. and Hay, E.M. 2005: Effectiveness of manual therapy or pulsed shortwave diathermy in addition to advice and exercise for neck disorders: a pragmatic randomized controlled trial in physical therapy clinics. Arthritis and Rheumatology 53, 214-22.

Eccles, M.P., Armstrong, D., Baker, R., Cleary, K., Davies, H., Davies, S., Glasziou, P., Ilott, I., Kinmonth, A.L., Leng, G., Logan, S., Marteau, T., Michie, S., Rogers, H., RycroftMalone, J. and Sibbald, B. 2009: An implementation research agenda. Implement Science 4, 18.

Elliott, A.M., Smith, B.H., Hannaford, P.C., Smith, W.C. and Chambers, W.A. 2002: The course of chronic pain in the community: results of a 4-year follow-up study. Pain 99, 299-307.

Primary Health Care Research \& Development 2010; 11: 4-16 
Felson, D.T., Lawrence, R.C., Dieppe, P.A., Hirsch, R., Helmick, C.G., Jordan, J.M., Kington, R.S., Lane, N.E., Nevitt, M.C., Zhang, Y., Sowers, M., McAlindon, T., Spector, T.D., Poole, A.R., Yanovski, S.Z., Ateshian, G., Sharma, L., Buckwalter, J.A., Brandt, K.D. and Fries, J.F. 2000: Osteoarthritis: new insights. Part 1: the disease and its risk factors. Annals of Internal Medicine 133, 635-46.

Felson, D.T., Naimark, A., Anderson, J., Kazis, L., Castelli, W. and Meenan, R.F. 1987: The prevalence of knee osteoarthritis in the elderly. The Framingham Osteoarthritis Study. Arthritis and Rheumatology 30, 914-18.

Foster, N.E., Pincus, T., Underwood, M.R., Vogel, S., Breen, A. and Harding, G. 2003: Understanding the process of care for musculoskeletal conditions - why a biomedical approach is inadequate? Rheumatology 42, 401-04.

Foster, N.E., Thomas, E., Barlas, P., Hill, J.C., Young, J., Mason, E. and Hay, E.M. 2007: Acupuncture as an adjunct to exercise based physiotherapy for osteoarthritis of the knee: randomised controlled trial. British Medical Journal $335,436$.

Fritz, J.M., Cleland, J.A. and Brennan, G.P. 2007: Does adherence to the guideline recommendation for active treatments improve the quality of care for patients with acute low back pain delivered by physical therapists? Medical Care 45, 973-80.

Gatchel, R.J., Peng, Y.B., Peters, M.L., Fuchs, P.N. and Turk, D.C. 2007: The bio-psychosocial approach to chronic pain: scientific advances and future directions. Psychology Bulletin 133, 581-624.

Gureje, O., Von Korff, M., Kola, L., Demyttenaere, K., He, Y., Posada-Villa, J., Lepine, J.P., Angermeyer, M.C., Levinson, D., de Girolamo, G., Iwata, N., Karam, A., Guimaraes, , Borges, G.L., de Graaf, R., Browne, M.O., Stein, D.J., Haro, J.M., Bromet, E.J., Kessler, R.C. and Alonso, J. 2008: The relation between multiple pains and mental disorders: results from the World Mental Health Surveys. Pain 135, 82-91.

Hay, E.M., Foster, N.E., Thomas, E., Peat, G., Phelan, M., Yates, H.E., Blenkinsop, A. and Sim, J. 2006: Effectiveness of community physiotherapy and enhanced pharmacy review for knee pain in people aged over 55 presenting to primary care: pragmatic randomised trial. British Medical Journal 33, 995-98.

Hay, E.M., Mullis, R., Lewis, M., Vohora, K., Main, C.J., Watson, P., Dziedzic, K.S., Sim, J., Minns-Lowe, C. and Croft, P.R. 2005: Comparison of physical treatments versus a brief pain-management programme for back pain in primary care: a randomised clinical trial in physiotherapy practice. Lancet 365, 2024-30.

Hemingway, H. 2006: Prognosis research: why is Dr Lydgate still waiting? Journal of Clinical Epidemiology 59, 1229-38.

Henschke, N., Maher, C.G. and Refshauge, K.M. 2007: Screening for malignancy in low back pain patients: a systematic review. European Spine Journal 16, 1673-79.

Hill, J.C., Dunn, K.M., Lewis, M., Mullis, R., Main, C.J., Foster, N.E. and Hay, E.M. 2008: A primary care back pain

Primary Health Care Research \& Development 2010; 11: 4-16 screening tool: identifying patient subgroups for initial treatment. Arthritis and Rheumatology 59, 632-41.

Holden, M.A., Nicholls, E.E., Hay, E.M. and Foster, N.E. 2008: Physical therapists' use of therapeutic exercise for patients with clinical knee osteoarthritis in the United Kingdom: in line with current recommendations? Physical Therapy 88, 1109-21.

Huas, D., Pouchain, D., Gay, B., Avouac, B., Bouvenot, G. and the French College Of Teachers. 2006: Assessing chronic pain in general practice: are guidelines relevant? A cluster randomised controlled trial. European Journal of General Practice 12, 52-57.

Jagger, C., Matthews, R., Spiers, N., Brayne, C., ComasHerrera, A., Robinson, T., Lindesay, J., and Croft, P. 2006: Compression or expansion of disability? Forecasting future disability levels under changing patterns of diseases. Wanless Social Care Review Research Report, Leicester Nuffield Research Unit, University of Leicester.

Jarvik, J.G., Hollingworth, W., Martin, B., Emerson, S.S., Gray, D.T., Overman, S., Robinson, D., Staiger, T., Wessbecher, F., Sullivan, S.D., Kreuter, W. and Deyo, R.A. 2003: Rapid magnetic Resonance-imaging vs radiographs for patients with low back pain: a randomized controlled trial. Journal of the American Medical Association 289, 2810-18.

Jellema, P., van der Windt, D.A., van der Horst, H.E., Twisk, J.W., Stalman, W.A. and Bouter, L.M. 2005: Should treatment of (sub)acute low back pain be aimed at psychosocial prognostic factors? Cluster randomised clinical trial in general practice. British Medical Journal 331, 84.

Jinks, C., Jordan, K. and Croft, P. 2006: Disabling knee pain another consequence of obesity: results from a prospective cohort study. BMC Public Health 6, 258.

Jinks, C., Nio Ong, B. and O'Neill, T.J. 2009: The Keele community knee pain forum: action research to engage with stakeholders about the prevention of knee pain and disability. BMC Musculoskeletal Disorders 10, 85.

Kadam, U.T., Schellevis, F.G., Lewis, M., van der Windt, D.A., de Vet, H.C., Bouter, L.M. and Croft, P.R. 2009: Does age modify the relationship between morbidity severity and physical health in English and Dutch family practice populations? Quality of Life Research 18, 209-20.

Kamaleri, Y., Natvig, B., Ihlebaek, C.M., Benth, J.S. and Bruusgaard, D. 2009: Change in the number of musculoskeletal pain sites: a 14-year prospective study. Pain 141, 25-30.

Kamaleri, Y., Natvig, B., Ihlebaek, C.M. and Bruusgaard, D. 2008: Localised or widespread musculoskeletal pain: does it matter? Pain 38, 41-46.

Kanaan, R.A., Lepine, J.P. and Wessely, S.C. 2007: The association or otherwise of the functional somatic syndromes. Psychosomatic Medicine 69, 855-59.

Keller, A., Hayden, J., Bombardier, C. and van Tulder, M. 2007: Effect sizes of non-surgical treatments of non-specific low-back pain. European Spine Journal 16, 1776-88.

Kennedy, A.P., Nelson, E., Reeves, D., Richardson, G., Roberts, C., Robinson, A., Rogers, A.E., Sculpher, M. 
and Thompson, D.G. 2004: A randomised controlled trial to assess the effectiveness and cost of a patient orientated self-management approach to chronic inflammatory bowel disease. Gut 53, 1639-45.

Larsson, B. and Sund, A.M. 2007: Emotional/behavioural, social correlates and one-year predictors of frequent pains among early adolescents: influences of pain characteristics. European Journal of Pain 11, 57-65.

Li, Y. and Begovich, A.B. 2009: Unravelling the genetics of complex diseases: susceptibility genes for rheumatoid arthritis and psoriasis. Semin. Immunology E-publication ahead of print.

Little, P., Lewith, G., Webley, F., Evans, M., Beattie, A., Middleton, K., Barnett, J., Ballard, K., Oxford, F., Smith, P., Yardley, L., Hollinghurst, S. and Sharp, D. 2008: Randomised controlled trial of Alexander technique lessons, exercise, and massage (ATEAM) for chronic and recurrent back pain. British Medical Journal 337, a884.

Lorig, K. 2002: Partnerships between expert patients and physicians. Lancet 359, 814-15.

Mallen, C., Peat, G., Thomas, E. and Croft, P. 2005: Severely disabling chronic pain in young adults: prevalence from a population-based postal survey in North Staffordshire. BMC Musculoskeletal Disorders 6, 42.

Mallen, C., Peat, G., Thomas, E. and Croft, P. 2006a: Is chronic pain in adulthood related to factors at birth? A populationbased case-control study of young adults. European Journal of Epidemiology 21, 237-43.

Mallen, C.D., Peat, G., Thomas, E. and Croft, P.R. 2006b: Is chronic pain in adulthood related to childhood factors? A population-based case-control study of young adults. Journal of Rheumatology 33, 2286-90.

Mallen, C.D., Peat, G., Thomas, E., Dunn, K.M. and Croft, P.R. 2007: Prognostic factors for musculoskeletal pain in primary care: a systematic review. British Journal of General Practice 57, 655-61.

McCormick, A., Fleming, D. and Charlton, J. 1995: Morbidity statistics from general practice. Fourth national study 1991-1992. London, UK: Office of Population Censuses and Surveys Series, MB5 No 3.

Miller, F.G. and Kaptchuk, T.J. 2008: The power of context: reconceptualising the placebo effect. Journal of the Royal Society of Medicine 101, 222-25.

Nielsen, L.A. and Henriksson, K.G. 2007: Pathophysiological mechanisms in chronic musculoskeletal pain (fibromyalgia): the role of central and peripheral sensitization and pain disinhibition. Best Practice Research Clinical Rheumatology 21, 465-80.

Ong, B.N. and Hooper, H. 2006: Comparing clinical and lay accounts of the diagnosis and treatment of back pain. Sociology of Health and Illness 28, 203-22.

Patten, S.B., Williams, J.V., Lavorato, D.H., Modgill, G., Jette?, N. and Eliasziw, M. 2008: Major depression as a risk factor for chronic disease incidence: longitudinal analyses in a general population cohort. General Hospital Psychiatry 30, 407-13.
Peat, G., Thomas, E. and Croft, P. 2006: Staging joint pain and disability: a brief method using persistence and global severity. Arthritis and Rheumatology 55, 411-19.

Porcheret, M., Jordan, K. and Croft, P. 2007: Primary Care Rheumatology Society. Treatment of knee pain in older adults in primary care: development of an evidence-based model of care. Rheumatology 46, 638-48.

Punnett, L., Prüss-Utuin, A., Nelson, D.I., Fingerhut, M.A., Leigh, J., Tak, S. and Phillips, S. 2005: Estimating the global burden of low back pain attributable to combined occupational exposures. American Journal of Industrial Medicine 48, 459-69.

Richardson, J.C., Ong, B.N. and Sim, J. 2007: Experiencing chronic widespread pain in a family context: giving and receiving practical and emotional support. Sociology of Health and Illness 29, 347-65.

Royal College of General Practitioners, Office of Population Censuses and Surveys, and Department of Health and Social Security. 1974: Morbidity statistics from general practice second national study 1970-71 - studies on medical and population subject no. 26. London: HMSO.

Salisbury, C., Foster, N.E., Bishop, A., Calnan, M., Coast, J., Hall, J., Hay, E., Hollinghurst, S., Hopper, C., Grove, S., Kaur, S. and Montgomery, A. 2009: 'PhysioDirect' telephone assessment and advice services for physiotherapy: protocol for a pragmatic randomised controlled trial. BMC Health Services Research 9, 136.

Saunders, K., Von Korff, M., Leresche, L. and Mancl, L. 2007: Relationship of common pain conditions in mothers and children. Clinical Journal of Pain 23, 204-13.

Savigny, P., Watson, P., Underwood, M. and Guideline Development Group. 2009: Early management of persistent non-specific low back pain: summary of NICE guidance. British Medical Journal 338, 1805.

Shaw, W.S., Linton, S.J. and Pransky, G. 2006: Reducing sickness absence from work due to low back pain: how well do intervention strategies match modifiable risk factors? Journal of Occupational Rehabilitation 16, 591-605.

Siddall, P.J. and Cousins, M.J. 2004: Persistent pain as a disease entity: implications for clinical management. Anaesthetics and Analgesia 99, 510-20.

Staal, J.B., Hlobil, H., van Tulder, M.W., Waddell, G., Burton, A.K., Koes, B.W. and von Mechelen, W. 2003: Occupational health guidelines for the management of low back pain: an international comparison. Occupational and Environmental Medicine 60, 618-26.

Stoller, E.P., Forster, L.E., Pollow, R. and Tisdale, W.A. 1993: Lay evaluation of symptoms by older people: an assessment of potential risk. Health Education Quarterly 20, 505-22.

Stucki, G., Boonen, A., Tugwell, P., Cieza, P. and Boers, M. 2007: The World Health Organisation International Classification of Functioning, Disability and Health: a conceptual model and interface for the OMERACT process. Journal of Rheumatology 34, 600-606.

Primary Health Care Research \& Development 2010; 11: 4-16 
Thomas, E., Dunn, K.M., Mallen, C. and Peat, G. 2008: A prognostic approach to defining chronic pain: application to knee pain in older adults. Pain 139, 389-97.

Thomas, E., Peat, G., Harris, L., Wilkie, R. and Croft, P.R. 2004: The prevalence of pain and pain interference in a general population of older adults: cross-sectional findings from the North Staffordshire Osteoarthritis Project (NorStOP). Pain 110, 361-68.

UK BEAM Trial Team. 2004: United Kingdom back pain exercise and manipulation (UK BEAM) randomized trial: effectiveness of physical treatments for back pain in primary care. British Medical Journal 329, 1377.

Von Korff, M. and Dunn, K.M. 2008: Chronic pain reconsidered. Pain 138, 267-76.

Von Korff, M. and Miglioretti, D.L. 2005: A prognostic approach to defining chronic pain. Pain 117, 304-13.

Waddell, G. 2004: The Back Pain Revolution. Edinburgh, UK: Churchill Livingstone.

Waddell, G., O'Connor, M., Boorman, S. and Torsney, B. 2007: Working Backs Scotland: a public and professional health education campaign for back pain. Spine 32, 2139-43.

Werner, E.L., Ihlebaek, C., Laerum, E., Wormgoor, M.E. and Indahl, A. 2008: Low back pain media campaign: no effect on sickness behaviour. Patient Education and Counselling 71, 198-203.
Westman, A., Linton, S.J., Ohrvik, J., Wahle?n, P. and Leppert, J. 2008: Do psychosocial factors predict disability and health at a 3-year follow-up for patients with non-acute musculoskeletal pain? A validation of the Orebro Musculoskeletal Pain Screening Questionnaire. European Journal of Pain 12, 641-49.

WHO. 2001: International classification of functioning, disability and health. ICF. Geneva, Switzerland: World Health Organisation.

Wilkie, R., Peat, G., Thomas, E. and Croft, P. 2007: Factors associated with restricted mobility outside the home in community-dwelling adults ages fifty years and older with knee pain: an example of use of the International classification of Functioning to investigate participation restriction. Arthritis and Rheumatology 57, 1381-89.

Woolf, A.D. and Akesson, K. 2001: Understanding the burden of musculoskeletal conditions. The burden is huge and not reflected in national health priorities. British Medical Journal 322, 1079-80.

Zhang, W., Moskowitz, R.W., Nuki, G., Abramson, S., Altman, R.D., Arden, N., Bierma-Zeinstra, S., Brandt, K.D., Croft, P., Doherty, M., Dougados, M., Hochberg, M., Hunter, D.J., Kwoh, K., Lohmander, L.S. and Tugwell, P. 2008: OARSI recommendations for the management of hip and knee osteoarthritis, Part II: OARSI evidence-based, expert consensus guidelines. Osteoarthritis Cartilage 16, 137-62. 